\title{
Functional echocardiography as a tool for the dynamic treatment evaluation in critically ill neonates
}

\section{Ecocardiografía funcional como una herramienta de evaluación dinámica del tratamiento en neonatos críticamente enfermos}

\author{
Ana L. Acevedo-Olguín ${ }^{1 *}$, Rodrigo Hernández-Benítez ${ }^{2}$, José Iglesias-Leboreiro, \\ Isabel Bernárdez-Zapata ${ }^{3}$, Moisés N. Gerardo-del Hoyo ${ }^{3}$, and Mario E. Rendón-Macías ${ }^{3}$
}

${ }^{1}$ Department of Neonatology; ${ }^{2}$ Department of Pediatrics, Pediatric Cardiology. Hospital Español de México; ${ }^{3}$ Unit of Research in Evidence Analysis and Synthesis, IMSS. Mexico City, Mexico

\begin{abstract}
Introduction: There is still controversy about the usefulness of functional echocardiography (FnEC) in critically ill neonates. Objective: The objective of the study was to analyze the usefulness of the FnEC in the treatment decisions in neonates admitted to a Neonatal Intensive Care Unit (NICU). Materials and methods: This was a 1-year prospective study in a NICU. A trained cardiologist performed a FnEC to $72 \mathrm{~h}$ of life patients to evaluate the cardiac function and heart structure. We analyzed the clinical decisions after the findings. Results: Thirty-seven neonates underwent two FnEC: at the diagnosis and at follow-up. Eleven patients (29.7\%) had structural and functional abnormalities, nine (24.3\%) only functional, seven (18.9\%) only structural, and in the rest, ten (27\%) were normal. One change in the management occurred in $70 \%$ of the patients. The main changes were to the ventilatory support (63\%), followed by inotropic support (19.5\%) and fluid intake (10.8\%). In all changes, we observed an improvement in the clinical conditions of the neonates. Conclusions: The FnEC allowed to determinate the cardiovascular structures and hemodynamic conditions of the patients and make more precise therapeutic modifications.
\end{abstract}

Key words: Neonate. Preterm. EcoFn. Treatment. Neonatal intensive care unit. Mexico.

\section{Resumen}

Introducción: Aún existe controversia sobre la utilidad de la ecocardiografía funcional (EcoFn) en la valoración cardiovascular de neonatos críticamente enfermos. Objetivo: Analizar la utilidad de la EcoFn en la modificación de tratamiento en neonatos ingresados a una Unidad de Cuidados Intensivos Neonatales (UCIN). Material y métodos: Estudio prospectivo en una UCIN durante un año mediante EcoFn realizada por un cardiólogo capacitado en pacientes en sus primeras 72 horas de vida extrauterina, con valoración de la funcionalidad cardiaca y presencia de alteraciones estructurales. Con base en los hallazgos se analizaron las modificaciones al tratamiento. Resultados: 37 neonatos fueron evaluados con EcoFn en dos ocasiones:

Correspondence:

*Ana Laura Acevedo-Olguín

E-mail: acevedolguin@gmail.com
Date of reception: $28-02-2019$

Date of acceptance: 15-08-2019

DOI: 10.24875/ACME.M20000076
Available online: $12-03-2020$ Arch Cardiol Mex (Eng). 2019;89(4):361-366 www.archivoscardiologia.com 2604-7063/@ 2019 Instituto Nacional de Cardiología Ignacio Chávez. Published by Permanyer. This is an open access article under the CC BY-NC-ND license (http://creativecommons.org/licenses/by-nc-nd/4.0/). 
una diagnóstica y otra de seguimiento. En 11 (29.7\%) se encontró daño estructural y funcional, en 9 (24.3\%) solo funcional, en 7 (18.9\%) solo estructural y en 10 (27\%) no se observaron alteraciones. En el $70 \%$ se realizó al menos un cambio de tratamiento. Los cambios más frecuentes fueron modificaciones al apoyo ventilatorio (63\%), seguido del apoyo aminérgico (19.5\%) y modificaciones en el aporte de líquidos (10.8\%). En todos los casos los cambios mejoraron las condiciones clínicas de los neonatos. Conclusiones: La EcoFn permitió determinar mejor las condiciones estructurales y hemodinámicas de los pacientes y realizar modificaciones terapéuticas más precisas.

Palabras clave: Neonato. Pretérmino. EcoFn. Ucin. Tratamiento. México.

\section{Introduction}

Continuous clinical evaluation of hemodynamic status in a critically ill neonate is essential to carry out actions aimed at preserving tissue perfusion and oxygenation, especially in vital organs ${ }^{1}$. This assessment is usually carried out through the recording of heart rate, blood pressure, capillary refill, and urine output ${ }^{2}$, which is variables that should be analyzed considering the changes associated with gestational age at birth ${ }^{3}$. In addition, the measurement of these variables can be difficult, especially if special equipment is not available and/or resorting to invasive monitoring is not wanted ${ }^{4}$. Therefore, other less aggressive and more reliable alternatives have been sought for this evaluation.

Functional echocardiography ( $\mathrm{FnECHO}$ ) was introduced about 10 years ago as a tool to support the continuous hemodynamic assessment of critically ill neonates. FnECHO enables: (a) obtaining evidence of structural alterations of the heart and large vessels, such as intracardiac and extracardiac short circuits; (b) assessing the myocardial function (ventricular filling and emptying volumes and contraction times), and (c) determining systemic and pulmonary flow pressures ${ }^{2}$.

Preload assessment is done through left ventricle (LV), right ventricle (RV), and inferior vena cava (IVC) evaluation; in case of emergencies, observing the "kissing ventricles" sign suggests hypovolemia, RV dilation may indicate overload or presence of pulmonary artery hypertension (PAH); it is always important to remember that, in neonates, the RV is slightly dominant after birth.

The dynamic complexity of transitional circulation, the response that an immature myocardium can have at the early stages of the neonatal period, the existence of physiological short circuits such as the oval foramen and patent ductus arteriosus (PCA), make for therapeutic decision to be a challenge. The role of the cardiologist in the neonatal intensive care unit (NICU) should focus not only on anatomical aspects but also on hemodynamics, and this should be continuously; several studies show that the systematic use of $\mathrm{FnECHO}$ allows cardiovascular compromise to be identified, enabling the neonatologist to make management changes and improve patient evolution in the short term ${ }^{3,5}$.

The spectrum of indications has increased and has practically become an extension of physical exploration; it is added to the assessment of usual clinical data, in an attempt to individualize treatment according to the specific pathophysiology on each situation ${ }^{3}$.

A potential advantage of this technique is its dynamic nature, which facilitates therapeutic decision-making based on the pathophysiological conditions of each patient, in addition to observing the changes subsequent to these modifications ${ }^{3,6}$. There are several global trials where changes in clinical treatment are reported in $30-60 \%$ of cases, and in some hospitals, this type of examination is considered mandatory in the management of the newborn with shock ${ }^{5,6}$.

One disadvantage is its characteristic of being operator-dependent since its accuracy depends on the training of the evaluating cardiologist ${ }^{4}$. In our hospital, this technique was implemented 5 years ago, and its impact on the care of our neonates has thus far not been assessed.

The purpose of this study is to report on the usefulness of $\mathrm{FnECHO}$ in the hemodynamic management of critically ill neonates from a NICU.

\section{Material and methods}

This was a descriptive study of a prospective cohort of neonates under the care of the NICU of the Hospital Español de México. The study was approved by the Hospital Español Research and Ethics Committee.

Preterm and full-term neonates were included at any moment of their stay at the NICU attended to during the period from March 1, 2017, to February 28, 2018. Over the course of the study, hospitalized neonates were assessed daily to detect those with any of the following data:

- Data consistent with persistent respiratory distress despite established ventilatory management 
- Data consistent with hemodynamic instability (hypotension, tachycardia or bradycardia, oliguria, and prolonged capillary refill)

- Maternal history with the risk of cardiac repercussion (mothers with systemic lupus erythematosus [SLE])

- Evidence of extracardiac congenital malformations and suspected congenital heart disease.

Once participation was approved by the parents or legal guardians, FnECHO evaluation was requested by the cardiology department.

The study was carried out at the cradle of the patient, using a Siemens Acuson X150 Vet $^{\circledR}$ Ultrasound Scanner with a 2.25-12-MHz S8 ${ }^{\circledR}$ Transducer. Measurements were carried out by a single observer, a pediatric cardiologist trained in echocardiography with 5 years of experience in this technique.

The echocardiographic assessment targeted mainly on the following aspects:

- Assessing the presence of patent ductus arteriosus and its repercussion (diameter of the pulmonary mouth, ductal speed, ratio between left atrium [LA] and aortic root, mitral E/A ratio, and short circuit direction)

- Assessing LV systolic and diastolic function: The shortening fraction (SF) and ejection fraction (LVEF) were assessed in $\mathrm{M}$ mode with parasternal views on a short and long axis or using the Simpson biplane method. The values regarded as normal were: AF between 26 and 46\%, normal LVEF, > 55\%.

Tissue Doppler: the myocardial performance index (TEI), which has demonstrated adequate correlation with global and regional ventricular contractility, was determined. Normal values were considered between 0.28 and 0.32 for both ventricles.

- Right ventricular function: Tricuspid annular plane systolic excursion (TAPSE) was determined in $M$ mode through the tricuspid lateral ring, with tricuspid ring longitudinal movement being measured in systole. It is a good parameter of the systolic function

- Pulmonary artery systolic pressure (PASP) estimation: It was estimated using a four-chamber view to obtain a good trace of tricuspid insufficiency, by means of CW Doppler; subsequently, right atrial pressure was added, which normally is $5-10 \mathrm{mmHg}$.

PASP formula $=4 \times(\mathrm{TI}$ velocity $) 2+$ RA pressure $(5-10 \mathrm{mmHg})$.

In the case of ductus arteriosus flow, it was determined based on its gradient minus systolic arterial pressure.

- Determining the presence of an atrial septal defect. - Systemic and pulmonary blood flow estimation.
- Systemic flow estimation of: It was carried out using the cross-sectional area (CSA), which was obtained by measuring the diameter at aortic leaflets insertion site at end of systole. The velocity time integral (VTI) was measured with PW Doppler at the proximal level of the aortic valve with an apical five-chamber view

- Systemic flow $(\mathrm{mL} / \mathrm{kg} / \mathrm{min})=\mathrm{CSA} \times \mathrm{VTI}-\mathrm{LV}$ output tract measurement $\times \mathrm{HR} /$ weight $(\mathrm{kg})$.

- Pulmonary flow estimation: It was carried out using the CSA, which was obtained by measuring end of systole diameter at the pulmonary leaflet insertion site. VTI was measured with PW Doppler at the pulmonary valve proximal level in a short-axis view.

Pulmonary flow $(\mathrm{mL} / \mathrm{kg} / \mathrm{min})=\mathrm{CSA} \times \mathrm{VTI}-\mathrm{RV}$ outflow tract measurement $\times \mathrm{HR} /$ weight $(\mathrm{kg})$.

- Determining fluid input increases or decreases. It was determined based on the measurements of LA in comparison with the aorta (Ao), in addition to a four-chamber view, an LA: Ao index > 1.4:1 in patients with PDA indicates data consistent with overload.

- IVC collapsibility index: IVC collapse through respiratory cycles is a good preload indicator in pediatric patients.

- Superior vena cava (SVC) flow measurement (SVC diameter and VTI).

In all assessments, the cardiologist was aware of the diagnoses and treatments received by the patients. After the evaluation, and based on the findings, the cardiologist suggested management recommendations to maintain or improve hemodynamic conditions of the neonate. The final decision on carrying them out was made by the neonatologist responsible for patient care. A second evaluation with $\mathrm{FnECHO}$ was carried at $72 \mathrm{~h}$ to determine if there were management-associated changes.

Information was obtained from each neonate regarding gestational age at birth, gender, days of life at the moment of the study, diagnoses at the time of the study, and the reason for requesting $\mathrm{FnECHO}$ and the treatment received at the time of assessment.

\section{Statistical analysis}

To better determine FnECHO usefulness, the patients were classified after assessment in four groups: (I) with a structurally and functionally normal heart; (II) with a structurally abnormal and functionally normal heart; (III) with a structurally normal but functionally abnormal heart, and (IV) with a structurally and functionally abnormal heart. According to the findings, the decisions 
Table 1. Characteristics of the studied newborns

\begin{tabular}{|l|c|}
\hline Characteristics & Total $\mathbf{3 7}(\%)$ \\
\hline Gender & \\
Female & $14(37.8)$ \\
Male & $23(62.2)$ \\
\hline Weeks of gestation & \\
\hline 28 & $3(8.1)$ \\
$28-33$ & $11(29.7)$ \\
$34-36$ & $15(40.5)$ \\
$37-41$ & $8(21.6)$ \\
\hline Birth weight & \\
\hline 1 kg & $4(10.8)$ \\
\hline $1-1.5$ kg & $6(16.2)$ \\
1.5-1.990 kg & $8(21.6)$ \\
$2-2.499$ kg & $6(16.2)$ \\
\hline 2.5 & $13(35.1)$ \\
\hline Days of life at the moment of the study & \\
Median & 2 \\
(Min-01-03-max) & $(1-1-3-30)$ \\
\hline Main diagnosis & \\
Respiratory distress syndrome & $20(54.1)$ \\
Transient tachypnea of the newborn & $4(10.8)$ \\
Sepsis & $3(8.1)$ \\
Extreme prematurity & $3(8.1)$ \\
Hydrops fetalis & $2(5.4)$ \\
Child of a mother with SLE & $2(5.4)$ \\
Diaphragmatic hernia & $1(2.7)$ \\
Esophageal atresia & $1(2.7)$ \\
Perinatal asphyxia & $1(2.7)$ \\
\hline
\end{tabular}

SLE: systemic lupus erythematosus.

considered by the echocardiologist were summarized as: (1) changes in fluid requirements, (2) aminergic drug support, (3) ventilatory management, and (4) use of diuretics. A descriptive analysis with simple and percentage-relative frequencies was carried out. The statistical analysis was performed with the support of the SPSS ${ }^{\circledR}$ statistical program ${ }^{14}$.

\section{Results}

As shown in table 1, 37 neonates were studied; there were more male patients and the most common age group was that of late premature infants. $79.4 \%$ were premature; as for weight, there were patients from $<1 \mathrm{~kg}$ to more than $2.5 \mathrm{~kg}$. The FnECHO assessment was performed on average at 2 days of life. The same table shows the diagnoses for which the neonates were being treated at the NICU, with respiratory distress syndrome being the main reason.

In all patients, the examination could be fully carried out, with a variation in execution time of between 15 and $20 \mathrm{~min}$.
Table 2. Echocardiographic findings in 37 neonates by $\mathrm{FnECHO}$

\begin{tabular}{|l|c|}
\hline $\begin{array}{l}\text { Echocardiographic findings in } \mathbf{3 7} \\
\text { neonates by FnECHO }\end{array}$ & Total \\
\hline FnECHO findings & $\mathbf{n}(\%)$ \\
\hline Patent ductus arteriosus & $18(48.6)$ \\
\hline PAH & $13(35.1)$ \\
\hline Volume overload & $4(10.8)$ \\
\hline Minuscule VSD & $3(8.1)$ \\
\hline Persistent fetal circulation & $1(2.7)$ \\
\hline Low cardiac output & $1(2.7)$ \\
\hline Tricuspid insufficiency & $1(2.7)$ \\
\hline Endocarditis & $1(2.7)$ \\
\hline
\end{tabular}

Some patients had more than one finding in the study.

FnECHO: functional echocardiography; $\mathrm{PAH}$ : pulmonary arterial hypertension; VSD: ventricular septal defect.

In 27 patients, $72.9 \%$ detecting at least one abnormal data was possible. The main findings are presented in table 2. The most common structural anomaly was evidence of patent ductus arteriosus (48.6\%), followed by ventricular septal defect (8.1\%). As for cardiac function, evidence of pulmonary hypertension predominated $(35.1 \%)$ followed by volume overload $(10.8 \%)$. Of note, one patient of the study had evidence of endocarditis as the cause of hemodynamic instability.

Table 3 shows recommendations issued for management based on $\mathrm{FnECHO}$ findings. In the ten patients, in whom $\mathrm{FnECHO}$ showed structural and functional normality, this allowed suggesting a decrease in ventilatory support in $70 \%$ due to patient improvement, and in the remaining $30 \%$, continuing with the established management.

When only structural damage was observed (nine patients), given the high frequency of patent ductus arteriosus, the recommendations were addressed to the modification of ventilatory support to improve oxygenation to favor closure. Only in one patient, modifying fluid input was also suggested.

In those patients in whom there was hemodynamic repercussion (defined as cardiac output below normal values, moderate to severe valvular insufficiency, PAH or LVEF, and AF below normal values) in structurally normal hearts (seven patients), the study enabled different modifications to be made both in ventilatory management, aminergic support, and fluid intake. The most 
Table 3. Management decisions after assessment with functional echocardiography (FnECHO)

\begin{tabular}{|c|c|c|c|c|}
\hline \multicolumn{5}{|c|}{ Management decisions after assessment with FnECHO } \\
\hline & $\begin{array}{l}\text { Normal structure } \\
\text { and function } \\
\qquad \mathbf{n}=10\end{array}$ & $\begin{array}{l}\text { Structural damage } \\
\text { normal function } \\
\qquad n=9\end{array}$ & $\begin{array}{c}\text { Normal structure } \\
\text { altered function } \\
\qquad \mathbf{n = 7}\end{array}$ & $\begin{array}{l}\text { Structural damage } \\
\text { and altered function } \\
\qquad n=11\end{array}$ \\
\hline Increase in fluid intake & & & $1(14.2 \%)$ & \\
\hline Start of aminergic support & & & $3(42.8 \%)$ & $5(45.4 \%)$ \\
\hline Discontinuation of aminergic support & & & $1(14.2 \%)$ & \\
\hline Increase in ventilatory support & & $8(88.8 \%)$ & $6(85.7 \%)$ & $4(36.3 \%)$ \\
\hline Decrease in ventilatory support & $7(70 \%)$ & $2(22.2 \%)$ & & $2(18.1 \%)$ \\
\hline Decrease in liquid intake & & $1(11.1 \%)$ & $3(42.8 \%)$ & $1(9 \%)$ \\
\hline Start of diuretics & & & $2(28.5 \%)$ & \\
\hline Total changes & 7 & 11 & 16 & 12 \\
\hline
\end{tabular}

More than one management change could be made in a single patient.

common was an increase in ventilatory support, aminergic support, and fluid intake restriction.

Finally, in those patients with cardiac dysfunction in hearts with any structural alteration (11 patients), FnECHO allowed suggesting specific changes in ventilation, aminergic support, and fluid management. Five patients had a LVEF $<55 \%$, with the presence of relaxation times prolongation and isovolumetric contraction, reflecting an elongated TEI (>0.32); in these patients, starting amines was suggested; in one case, ventilatory support increase was also suggested; in one case, a dilated IVC was observed, with right cavities growth, and mild to moderate tricuspid and pulmonary insufficiency, with fluid decrease being therefore indicated. In three cases, a ventilatory support increase was suggested due to data consistent with right ventricular dysfunction, presence of moderate to severe TI, Iow TAPSE, RV TEl alteration or interventricular septal shift. Finally, in two cases, ventilatory support decrease was suggested, since they showed an adequate right ventricular function, they had PDA but with a slight impact on left ventricular function.

In all cases, it could be demonstrated that the control $\mathrm{FnECHO}$ at $72 \mathrm{~h}$ showed improvement in cardiovascular function.

\section{Discussion}

Over the past two decades, the incorporation of $\mathrm{FnECHO}$ as a non-invasive tool to the diagnosis of structural and functional conditions of critically ill neonates in intensive care units has increased. However, its usefulness has been little evaluated and therefore, this work shows our experience with its use for 1 year. As shown in the results, we can say that in virtually all our patients, FnECHO provided useful information for management. In $70 \%$ of them, it directly provided data for treatment changes, and in the remaining $30 \%$, it confirmed the adequacy of already-established management.

Two aspects our study contributes with are:

- On the one hand, the decision to carry out FnECHO assessments as a usual procedure in every critically ill newborn, conversely to observations in the previous studies $^{3,7}$, where the $\mathrm{FnECHO}$ indication has been especially in case of doubts in the diagnosis and treatment of patent ductus arteriosus, or in neonates with hemodynamic instability ${ }^{10,12}$. This difference may well explain the largest number of management modifications in our study (70\%) in comparison with those reported in other studies, which range from 30 to $51 \%$. In our study, assessment is intended for both structural and functional diagnostic purposes.

- The other different aspect is the performance by a cardiologist pediatrician. This contribution has its advantages, since it improves structural and functional diagnostic accuracy, given the higher level of training of this physician. One of the common criticisms of the use of $\mathrm{FnECHO}$ is the possibility of diagnostic, especially structural, errors, when a neonatologist performs the assessment ${ }^{4,8}$. On the other side, the fact of being carried out by a cardiologist has the limitation of expert availability; one reason for 
the worldwide interest in incorporating this tool in everyday and dynamic care of critically ill neonates has been the possibility of being performed by neonatologists themselves. Therefore, both in the US and in European countries, certified courses or training programs have been created $d^{6,9,13}$.

Our work still has limitations to be considered, with the first one being its observational nature, which is why we cannot assure whether the implementation or not of modifications would have occurred the same without the $\mathrm{FnECHO}$ examination ${ }^{10,11}$. For the future, we recommend conducting a study comparing $\mathrm{FnECHO}$ systematic use with another indicated tool under conditions of instability of the neonate.

On the other hand, our study provides information about the possible course of care in patients in whom FnECHO was systematically applied in a first assessment when the newborn may still have cardiocirculatory vulnerabilities, such as myocardial immaturity, presence of fetal short circuits, variations in pulmonary and systemic vascular resistance and, ultimately, the complex hemodynamic changes that occur during the transition process to extrauterine life.

In other studies, it has been assessed with successive measurements. In the study by Khakmar et al. ${ }^{7}$, patients had an average of two assessments, and in the study by Corredera et al. up to an average of three ${ }^{3}$. Therefore, the usefulness of an initial assessment should also be considered in the future, where the structural aspect will be paramount, as well as repeated functional studies tailored to the requirements of each patient.

There is still no solid evidence demonstrating a positive impact of the use of $\mathrm{FnECHO}$ in the NICU on patient prognosis; more randomized trials are needed to clarify if $\mathrm{FnECHO}$ modifies patient evolution, as well as a cost-effectiveness evaluation of $\mathrm{FnECHO}$ systematic implementation as a tool within the NICU for patient survival and health status at discharge.

\section{Conclusions}

FnECHO showed to be a safe and non-invasive assessment tool to better determine the cardiovascular structure and hemodynamic conditions of neonates. With the obtained information, it is possible to support the neonatologist in timely and appropriate therapeutic decision-making.

\section{Funding}

The author declares that this work has not received any source of external funding.

\section{Conflicts of interest}

None.

\section{Ethical disclosures}

Protection of people and animals. The authors declare that no experiments were performed on humans or animals for this study.

Confidentiality of data. The authors declare that they have followed the protocols of their work center on the publication of patient data.

Right to privacy and informed consent. The authors declare that no patient data appear in this article.

\section{References}

1. Hernández R, Becerra R. Ecocardiografía funcional en cuidados intensivos neonatales: experiencia en un hospital de tercer nivel. Bol Med Hosp Infant Mex. 2016;73(5):325-30.

2. Arruza L, Corredera A. Ecocardiografía funcional en neonatología. An Pediatr Contin. 2014;12(2):78-84.

3. Corredera A, Rodríguez MJ, Arévalo P, Llorente B, Moro M, Arruza L. Ecocardiografía funcional en cuidados intensivos neonatales: experiencia en una unidad española a lo largo de un año. An Pediatría. 2014; 81(3):167-73.

4. Tissot C, Muehlethaler V, Sekarski N. Basics of functional echocardiography in children and neonates. Front Pediatr. 2017;5:235.

5. Moss S, Kitchiner DJ, Yoxall CW, Subhedar NV. Evaluation of echocardiography on the neonatal unit. Arch Dis Child Fetal Neonatal Ed. 2003;88(4):F287-9; discussion F290-1.

6. Kluckow M, Seri I, Evans N. Functional echocardiography: an emerging clinical tool for the neonatologist. J Pediatr. 2007;150(2):125-30.

7. Khamkar A, Pradeep S, Maheswari R, Patnaik S, Malshe N, Kalrao V, et al. Functional neonatal echocardiography: Indian experience. J Clin Diagn Res. 2015;9(12):SC11-4.

8. Mertens L, Seri I, Marek J, Arlettaz R, Barker P, McNamara P, et al. Targeted neonatal echocardiography in the neonatal intensive care unit: Practice Guidelines and Recommendations for Training: Writing group of the American Society of Echocardiography (ASE) in collaboration with the European Association of Echocardiography (EAE) and the Association for European Pediatric Cardiologists (AEPC). Eur J Echocardiogr. 2011;12(10):715-36

9. Singh Y. Echocardiographic evaluation of hemodynamics in neonates and children. Front Pediatr. 2017;5:201

10. Noritomi DT, Vieira ML, Mohovic T, Bastos JF, Cordioli RL, Akamine N, et al. Echocardiography for hemodynamic evaluation in the intensive care unit: Shock. 2010;34(Suppl 1):59-62.

11. Rolland A, Shankar-Aguilera S, Diomandé D, Zupan-Simunek V, Boileau P. Natural evolution of patent ductus arteriosus in the extremely preterm infant. Arch Dis Child Fetal Neonatal Ed. 2015;100(1):F55-8.

12. Arlettaz R. Echocardiographic evaluation of patent ductus arteriosus in preterm infants. Front Pediatr. 2017:5:147.

13. Nguyen J, Amirnovin R, Ramanathan R, Noori S. The state of point-of-care ultrasonography use and training in neonatal-perinatal medicine and pediatric critical care medicine fellowship programs. J Perinatol. 2016;36(11):972-6. 